\title{
The Testing and Data Analyzing of Automobile Braking Performance
}

\author{
Peijiang Chen \\ School of Automobile, Linyi University, Shandong, 276000, China \\ chenpeijiang@163.com
}

Keywords: Braking performance, Roller opposite force, Brake tester, Data analyzing

\begin{abstract}
The braking performance is one of the main performances of automobiles. It directly affects the traffic safety, which is crucial to the vehicle safe driving. The three evaluation parameters of automobile braking performance are analyzed and the two commonly used detection methods are discussed and compared. The braking performance is detected based on the roller opposite force type automobile brake tester. The experiment results show that the measurement data have good consistency, and the braking performance detection can provide basis for the automobile fault diagnosis and ensure the traffic safety.
\end{abstract}

\section{Introduction}

Since the automobile was invented, it quickly became one of the most important traffic tools on land. Through constant development, the modern automobile is composed of a series of complex structures and systems which are mutually coordinate. The braking system is one of the most important systems. For the whole automobile, the brake system can make the car slow down and also make the vehicle stay in the parking station.

People enjoy comfort and convenience brought by the cars, at the same time, they also sustain the loss of life and property by the traffic accident. For the serious traffic accidents due to the braking system, there are two main factors, one is the too large braking distance, and the other is the spin phenomenon caused by suddenly lost direction stability of the rear wheel. According to relevant statistics, in all the traffic accidents caused by the vehicle itself, about $45 \%$ are made by the braking system's breakdown [1]. Therefore, all major automobile manufacturers put more and more attention on the design and detection technology of the braking system.

The detection technology of automobile braking system were researched starting in the 1950s. Initially, the detection project was mostly single item and the testing equipment was simple [2]. At present, the vehicle detection process is automatic, secure, efficient and accurate. All kinds of new technologies and equipment are introduced all the time.

On the basis of analyzing the relevant technologies and standards of the automobile braking performance testing, the real vehicles are tested and the experiment data are analyzed. The relevant parameters of braking performance are obtained and compared with national standards. Then, the test conclusion can be obtained which can provide the guarantee for the automobile safety driving.

\section{Braking system and performance evaluation parameters}

\section{Braking system}

The braking system is composed of two main components: brake, braking and driving mechanism. The brake is equipped with retarder, which is a part of the auxiliary braking system, and its main function is to produce the force of impeding the movement or movement trend of the vehicle [3].

The braking and driving mechanism is very complex, including a plurality of devices, such as energy supplying device, control device, braking force regulator, transmission device, additional device, etc. The energy supplying device is to provide and regulate the braking energy. The control device is to generate braking action and control the braking effect. The transmission device is to transfer the braking energy to brake. 
A qualified brake system must have three basic functions, namely service brake, emergency brake and parking brake. A good braking system should have the following characteristics.

(1) Stable braking performance

The distribution of braking force on front and rear axles must be reasonable. The braking force on left and right wheel of the same axle must be the same, which can ensure to the maximum extent that there are not driving deflection, slide and other slip phenomenon during emergency braking.

(2) High working reliability

A qualified braking device has at least two independent pipelines for the driving brake. If one set of pipeline is suddenly unavailable, the driver can control braking system through another set of pipeline. The part of brake system must be complete and reliable, and it need to install security equipment and alarm devices.

(3) Ease of control

The braking system can be manipulated when the force is below the standard power, and it has good following characteristic,

(4) Good hysteretic nature

The delay time should be as short as possible. It includes the required time from the driver depressing the brake pedal to achieving the braking performance and the time from releasing brake pedal to removing brake completely.

(5) Good brake thermal stability

The friction plate of the brake has good anti-heat fading capability.

(6) Good water stability

When water or sludge goes into the friction plate, the friction factor on the surface can resume normal parameters.

(7) Little brake pollution

When the automobile is braking, the noise cannot be large. At the same time, the emission of harmful gases should be reduced as far as possible in the barking process.

(8) Can adjust the brake clearance

Wearing can make the brake mechanism produce clearance. Therefore, the braking system must have the mechanism that can eliminate the clearance and be agree to operate the mechanism.

\section{Evaluation parameters of braking performance}

There are three factors to evaluate the braking performance of an automobile.

(1) Braking efficiency

The braking efficiency refers to the distance from the emergency braking to full stopping when the automobile drives at predetermined speed on a well road [4]. It is a basic index for the evaluation of automobile braking performance, mainly including ground braking force, braking force, braking deceleration, braking distance and braking time.

(2) Constancy of braking efficiency

In a variety of environments, automobiles can encounter a variety of unexpected situation, including reduction and recession of braking capacity. The constancy of braking efficiency means that the automobile can overcome the declination of braking ability and quickly restore the braking capacity. The recession of braking capacity can be divided into two types, heat fading and water fading [5].

(3) Direction stability

If the driving direction is not stable, the automobile may happen braking deviation, rear axle slip or front wheel losing steering ability and other dangerous situation during emergency braking process. It can make the automobile get out of control, leave the original direction. There is even serious traffic accidents, such as driving into the other running track, collision with other vehicles or other serious traffic accidents. 


\section{Detection methods and standards of braking system}

\section{Detection methods of braking system}

The braking performance is very critical to automobile safety, then it is important and necessary to detect vehicle braking performance. In the field of braking performance detection, the relevant government departments have promulgated corresponding laws and regulations specifically.

At present, there are a lot of methods to test the braking performance. They can be divided into two methods: road test methods and bench test methods [6]. The former should be realized outside and the latter can be done indoors. The two detection methods need quite different conditions. When an automobile is tested with the two methods respectively, the detection results of the same parameter may be different.

(1) Road test method

The method is so simple and intuitive that anyone can see the dynamic change of braking performance in the process of moving directly by the testing instrument. At the same time, it can comprehensively reflect the relationship between the braking system and other systems of the automobile, such as steering mechanism. Road test method also has some shortcomings. It cannot reflect the specific braking condition of all wheels, only can detect the braking system from the view of whole vehicle. Once the braking system fails, the fault position cannot be quickly found out. The detection results of road test method can be affected by many reasons, such as human factor, road condition, weather, temperature, humidity, and so on.

(2) Bench test method

The method is tested indoors, so it is not affected by external conditions. The test can be carried out with many times, then the detailed experiment data can be gotten. But the method has one disadvantage that it must be equipped with some large equipment and the corresponding testing site [7]. Due to its advantages of rapid, accurate, economic and security, this method gradually gets domestic and international attention and has been used widely. There are many kinds of braking testing benches. They can be divided into counter force type and inertia type, and also can be divided into roller type and the plate type. At present, there are two widely used testing platforms, they are single axle roller counter-force braking test system and plate type braking test system.

In the actual detection process, it requires high speed and high reliability, then the bench test method are adopted mostly. Only when there are questions for the measurement data of the method, the road test method can be used.

\section{Detection standards of automobile braking performance}

Since the performance of automobile braking systems is closely related to traffic safety, then the testing requirements of braking performance are stated by the relevant national standards.

(1) Percentage requirements of braking force

When tested in the braking tester, the braking force should meet the specific requirements, as shown in Table 1.

Table 1 Braking force requirement in bench test method

\begin{tabular}{ccccc}
\hline \multirow{2}{*}{ Automobile type } & \multicolumn{2}{c}{$\begin{array}{c}\text { Percentage of total braking force to vehicle } \\
\text { quality (\%) }\end{array}$} & $\begin{array}{c}\text { Percentage of axle braking and axle load } \\
(\%)\end{array}$ \\
\cline { 2 - 5 } & No-load & Full load & Front axle & Rear axle \\
\hline Passenger car & $\geq 60$ & $\geq 50$ & $\geq 60$ & $\geq 20$ \\
$\begin{array}{c}\text { Articulated vehicle, } \\
\text { combination vehicle }\end{array}$ & $\geq 55$ & $\geq 45$ & - & - \\
Other cars & $\geq 60$ & $\geq 50$ & $\geq 60$ & $\geq 60$ \\
\hline
\end{tabular}

(2) Balance requirements of braking force

In the whole process of braking force increasing, two maximums are measured, one is the maximum of braking force difference between left and right wheel, the other is the bigger of the 
maximums of the left and right wheel braking forces. The ratio of the two values should be meet the specific requirement, as shown in Table 2.

Table 2 Balance requirements of braking force in bench test method

\begin{tabular}{cccc}
\hline \multirow{2}{*}{ Automobile type } & Front axle & \multicolumn{2}{c}{ Rear axle (and other axles) } \\
\cline { 3 - 4 } & & Braking force $\geq 60 \%$ of axle load & Braking force $<60 \%$ of axle load \\
\hline New registered car & $\leq 20 \%$ & $\leq 24 \%$ & $\leq 8 \%$ \\
Car in use & $\leq 24 \%$ & $\leq 30 \%$ & $\leq 10 \%$ \\
\hline
\end{tabular}

(3) Braking harmony time requirements

For different braking modes, the harmony times are different, as shown if Table 3.

Table 3 Braking harmony time requirement in bench test method

\begin{tabular}{cccc}
\hline Braking type & Hydraulic braking & Air braking & Articulated vehicle, combination vehicle \\
Harmony time (s) & $\leq 0.35$ & $\leq 0.6$ & $\leq 0.8$ \\
\hline
\end{tabular}

(4) Wheel drag ratio requirements

The drag force of every wheel should be less than or equal to $10 \%$ of wheel load.

(5) Requirements of qualification evaluation

When using bench test method to detect the brake performance of an automobile, if the former four items' requirements are satisfied, the detection result of the braking performance is qualified.

\section{Data analysis of braking performance testing}

In the braking performance testing laboratory, using the roller counter-force brake test system tests an automobile in use, the experimental results are gotten, as shown in Table 4.

Table 4 Testing data of braking performance detection

\begin{tabular}{|c|c|c|c|c|c|c|c|c|c|c|c|c|c|}
\hline \multirow[t]{2}{*}{ Project } & \multicolumn{2}{|c|}{$\begin{array}{c}\text { Wheel ( axle ) } \\
\text { weight (kg) }\end{array}$} & \multicolumn{2}{|c|}{$\begin{array}{c}\text { Maximum } \\
\text { braking force } \\
(\mathrm{N})\end{array}$} & \multicolumn{2}{|c|}{$\begin{array}{l}\text { Maximum } \\
\text { difference }\end{array}$} & \multirow{2}{*}{$\begin{array}{l}\text { Braking } \\
\text { rate } \\
(\%)\end{array}$} & \multirow{2}{*}{$\begin{array}{c}\text { Unba } \\
\text { lance } \\
\text { rate } \\
(\%)\end{array}$} & \multicolumn{2}{|c|}{ Drag rate $(\%)$} & \multirow{2}{*}{$\begin{array}{l}\text { Item } \\
\text { concl } \\
\text { usion }\end{array}$} & \multirow{2}{*}{$\begin{array}{l}\text { Project } \\
\text { conclu } \\
\text { sion }\end{array}$} & \multirow{2}{*}{$\begin{array}{l}\text { Item } \\
\text { times }\end{array}$} \\
\hline & Left & Right & Left & Right & Left & Right & & & Left & Right & & & \\
\hline Axle 1 & 350 & 350 & $\begin{array}{l}3386.4 \\
2704\end{array}$ & $\begin{array}{c}2627.1 \\
2629\end{array}$ & $\begin{array}{c}3379.8 \\
4863\end{array}$ & $\begin{array}{c}2448.5 \\
0562\end{array}$ & 85.9 & 27.6 & 21.6 & 24.3 & $00 \times x$ & $x$ & 2 \\
\hline Axle 2 & 300 & 300 & $\begin{array}{c}2063.4 \\
2465\end{array}$ & $\begin{array}{c}2078.2 \\
4805\end{array}$ & $\begin{array}{c}1274.5 \\
81\end{array}$ & $\begin{array}{c}680.92 \\
31\end{array}$ & 69.0 & 28.6 & 25.2 & 32.9 & $00 \times x$ & $x$ & 2 \\
\hline Parking & \multicolumn{2}{|c|}{1300} & $\begin{array}{l}1989.2 \\
3326\end{array}$ & $\begin{array}{c}1652.7 \\
3836\end{array}$ & & 28.0 & & \multirow{2}{*}{\multicolumn{2}{|c|}{ - }} & 0 & 0 & \\
\hline Vehicle & \multicolumn{2}{|c|}{1300} & \multicolumn{2}{|c|}{10155.22603} & & & 78.1 & & & & o & o & \\
\hline
\end{tabular}

According to Table 4, it can be seen that the testing result of the braking performance detection is unqualified. The braking system threatens the driving safety at any time. It does not fit to drive on the road, and it is need to find out and maintain the fault.

\section{Conclusions}

With the development of the automobile industry, the detection of automobile performance has become increasingly important, especially the braking system which is related to personal safety. On the basis of analyzing the automobile braking system and performance testing standard, using the roller counter-force brake test system, the braking performance of automobile is tested and the 
corresponding data is gotten. The detection result of automobile braking performance can provide the basis for fault diagnosis and maintenance.

\section{Acknowledgement}

This study is sponsored by the Science and Technology Development Planning Project of Shandong Province (No. 2013YD05004), People's Republic of China.

\section{References}

[1] S. P. Jung, K. J. Jun, T. W. Park, J. H. Yoon, Development of the Brake System Design Program for a Vehicle, International Journal of Automotive Technology. 9(1) (2008) 79-84.

[2] M. Pana, G. Liu, Study on Vehicle Operating Safe State Monitoring Parameter and Measurement Model, Procedia Engineering. 29 (2012) 2496-2500.

[3] M. Hu, Z. Yang, Comparative Study on Flatbed and Opposite Force Roller Brake Tester, China Measurement \& Test. 37(6) (2011) 31-33.

[4] T. Zhang, Research on the Test System of Roller Opposite Forces Type Automobile Braking Tester, Changchun, China, Jilin University, (2006).

[5] W. Xu, M. Zang, S. Yu, Research on the Test Standard of Passenger Car Braking Performance, Automobile Technology. (8) (2018) 38-41.

[6] Y. Chen, Design on the Detection System of Vehicle Braking Performance, Test Technology and Testing Machine. 50(4) (2010) 54-57.

[7] P. Chen, Study on Vehicle Braking Performance Detection System, Fifth International Conference on Advanced Computational Intelligence, Nanjing, China, IEEE, (2012) 1009-1012. 